\title{
Experimental and mechanical model for predicting the behaviour of minor axis beam-to-column semi-rigid joints
}

\author{
L.R.O. de Lima ${ }^{a}$, S.A.L. de Andrade, \\ ${ }^{a}$ Civil Engineering Department, PUC-RIO_Pontifical Catholic University of Rio de Janeiro, Rio de Janeiro, Brazil \\ ${ }^{\mathrm{b}}$ Structural Engineering Department, UERJ_State University of Rio de Janeiro, Rio de Janeiro, Brazil \\ ${ }^{\mathrm{c}}$ Civil Engineering Department, University of Coimbra, Coimbra, Portugal
}

Received 8 October 2001

\begin{abstract}
This paper describes a series of experimental tests followed by finite element simulations produced to enable the prediction of moment resistance and rotation capacity of minor axis beam-to-column semi-rigid connections. These investigations motivated the development of a mechanical model to assess the connection's structural response. The mechanical model is based on the component method of design, in accordance with the Eurocode 3 specification. This philosophy implies that each joint component is represented by a spring possessing a non-linear force versus displacement $(F-\Delta)$ curve. The model was subsequently calibrated against experimental and finite element results previously performed. (C) 2002 Elsevier Science Ltd. All rights reserved.

Keywords: Structural steel connections; Semi-rigid joints; Finite element modelling; Component method; Mechanical models
\end{abstract}

\section{Introduction}

Traditionally, the steel portal frame design assumes that beam-to-column joints are rigid or pinned. Rigid joints, where no relative rotations occur between the connected members, transfer not only substantial bending moments, but also shear and axial forces. On the other extreme, pinned joints, are characterised by almost free rotation movement between the connected elements that prevents the transmission of bending moments [1].

Despite these facts, it is largely recognised that the great majority of joints does not exhibit such idealised behaviour. In fact, many joints transfer some bending moments associated with rotations. These joints are called semi-rigid, and their design should be performed according to their actual

\footnotetext{
* Corresponding author. Tel.: +55-21-2587-7537; fax: +55-21-2587-7537.

E-mail address: vellasco@eng.uerj.br, vellasco@uerj.br (P.C.G. da S. Vellasco).
} 


\begin{tabular}{|c|c|}
\hline \multicolumn{2}{|l|}{ Nomenclature } \\
\hline$a$ & distance between the loaded area and the supported face \\
\hline$b$ & loaded area width \\
\hline$c$ & loaded area height \\
\hline$d$ & column effective height \\
\hline$d_{1}, d_{2}$ and $d_{m}$ & head bolt dimensions \\
\hline$h_{r}$ & distance between the $r$ bolt row and the compression centre \\
\hline$k_{1}$ and $k_{2}$ & coefficients \\
\hline$k_{21}$ & column web in bending \\
\hline$k_{e}$ & elastic stiffness \\
\hline$k_{e f, r}$ & effective stiffness of the coupling series springs present in the $r$ bolt row \\
\hline$k_{e q}$ & equivalent stiffness of the coupling parallel springs \\
\hline$k_{i, r}$ & stiffness coefficient representing component $i$ relative to the bolt row $r$ \\
\hline$k_{p l}$ & plastic stiffness \\
\hline$l_{e f f}$ & effective length of the column web panel \\
\hline$m$ & distance between the top bolts and the top stiffener \\
\hline$q_{1}$ & total joint rotation \\
\hline$q_{2}$ & rotation of the rigid links (length $L_{c}$ ) in compression zone \\
\hline$q_{3 i}$ & rotation of the rigid links (length $L_{t}$ ) in tension zone \\
\hline$q_{4}$ & joint axial displacement \\
\hline$q_{5}$ & rotation of the tensile zone of the joint \\
\hline$t_{w c}$ & column web thickness \\
\hline$z_{e q}$ & equivalent lever arm \\
\hline$D$ & distance between the stiffeners (top and bottom) \\
\hline$F_{c}$ & compressive resistance \\
\hline$l$ & column web panel width \\
\hline$M_{j . R d}$ & bending moment response \\
\hline$S_{j, i n i}$ & joint initial stiffness \\
\hline$\alpha$ and $\beta$ & slenderness \\
\hline$\Delta_{f}$ & collapse displacement \\
\hline$\phi$ & rotation \\
\hline$\mu$ & column web slenderness \\
\hline$v$ & Poisson's coefficient \\
\hline$\theta$ & plastic hinge angle \\
\hline
\end{tabular}

structural behaviour. This is explained by the fact that in semi-rigid frames the internal force distributions, lateral displacement magnitudes, and collapse modes are functions of the joint flexibility. To estimate the actual behaviour of such joints, extensive research studies have been carried out over the past 25 years [2-5], leading to code specifications that enable the calculation of the moment rotation characteristics of major axis beam-to-column joints, beam-to-beam joints and column bases, as stated in the current draft version of Eurocode 3, Part 1.8 [6]. 


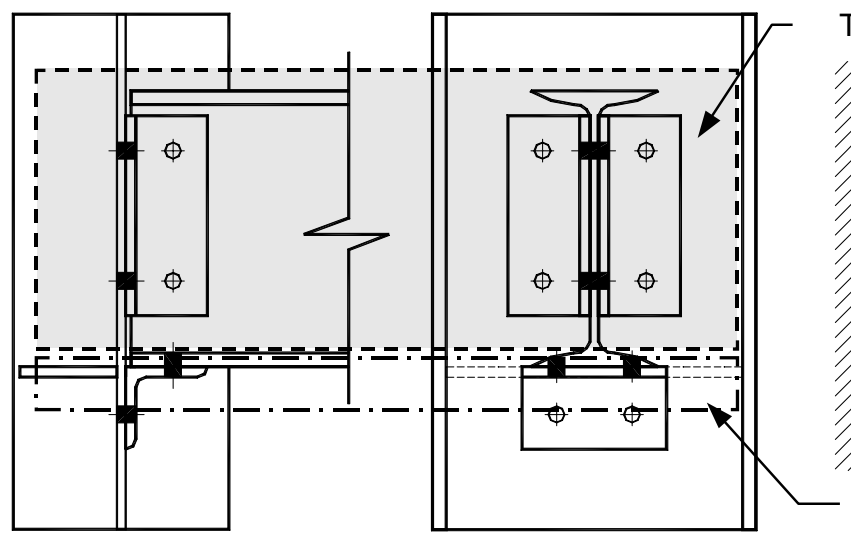

Tension zone

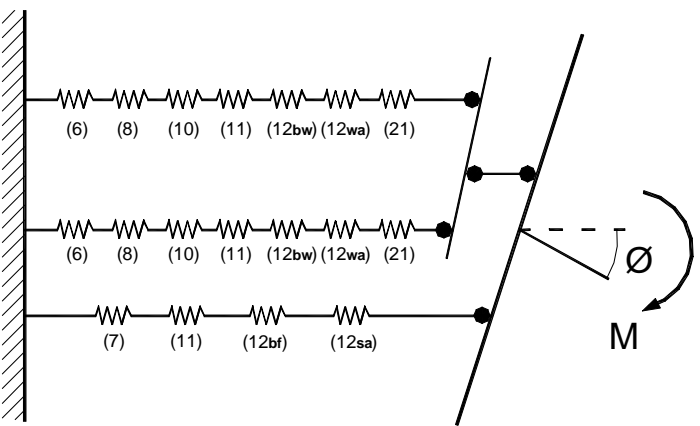

Compression zone

Fig. 1. Characterisation of the beam-to-column joints components.

When beam-to-column joints to the column minor axis are considered, the adopted design process generally assumes these joints as pinned. As explained previously, this is not true for the great majority of structural connections. Given that no code provisions currently exist for semi-rigid minor axis joints, it was decided to develop a mechanical model, in accordance with the general principles of Eurocode 3, Part 1.8 [6], to evaluate the connection's structural behaviour. The joints investigated were made with double web angles, a seat angle or a transverse web stiffener welded to the column web. A validation study of the proposed model was accomplished through comparisons with experimental test results performed at PUC-Rio (Pontifical Catholic University of Rio de Janeiro), Brazil [7] and finite element simulations using the ANSYS computer program [8].

\section{The mechanical model}

The behaviour of beam-to-column joints can be evaluated with the aid of the component method, largely adopted in research investigations and recently incorporated in Eurocode 3. From the theoretical point of view, it can be applied to any kind of connection, provided that the basic sources of strength and deformation are properly identified and modelled [9]. These sources, commonly denoted as joint components, represent a specific part of a connection that, dependent on the type of loading, make an identified contribution to one or more of its structural properties. A typical component model for a minor-axis joint composed by double web angles and a seat angle to the column minor axis is illustrated in Fig. 1. The relevant components are: (6) web angle in bending, (7) beam flange and web in compression, (8) beam web in tension, (10) bolts in tension, (11) bolts in shear, (12) beam web, beam flange, web angle and seat angle in bearing, and (21) column web in bending. In general, each of these components is characterised by a non-linear force-deformation curve, although simpler idealisations are possible, whenever only the resistance or the initial stiffness of the connection are required. A comprehensive description of the joint components is presented in Table 1. The application of the component method to steel connections requires the 
Table 1

Components description according to revised Annex $\mathrm{J}$ of the Eurocode 3

\begin{tabular}{ll}
\hline Component number & Component description \\
\hline 6 & Web angle in bending \\
7 & Beam web in compression \\
8 & Beam web in tension \\
10 & Bolts in tension \\
11 & Bolts in shear \\
$12^{b w}$ & Beam web in bearing \\
$12^{w a}$ & Web angle in bearing \\
$12^{b f}$ & Beam flange in bearing \\
$12^{s a}$ & Seat angle in bearing \\
21 & Column web in bending \\
\hline
\end{tabular}

following steps:

(i) selection of the relevant (active) components from a global list of components (20 different components are currently codified in Eurocode 3) for each bolt row;

(ii) evaluation of the force-deformation response of each component;

(iii) assembly of the active components (in series and in parallel) for the evaluation of the momentrotation response of the connection, using a representative mechanical model.

Minor-axis joints present a distinct behaviour that differentiates them from major axis joints between I-sections. In fact, the absence of a central stiffening web means that the column web must resist the tensile and compressive forces arising from the beam flanges in bending, akin to a plate supported on its vertical sides. This additional source of deformation [10] is represented by the new component 21 , introduced by the current investigation, that is substantially discussed in the following sections of this paper.

Although each component is characterised by a non-linear force-displacement $(F-\Delta)$ curve, their response can be approximated by multi-linear or simple polynomial models. Fig. 2 shows the case of a spring in compression represented by a bi-linear approximation. In this particular case four properties should be determined: elastic stiffness $\left(k_{e}\right)$; post-limit stiffness $\left(k_{p l}\right)$; compressive resistance $\left(F_{c}\right)$ and collapse displacement $\left(\Delta_{f}\right)$.

In order to obtain simple analytical solutions for the component model of Fig. 1, the formulation proposed by Silva et al. [11] is adopted. Fig. 3 illustrates the application of this procedure, which consists of: (i) replacing each non-linear spring by an equivalent elastic spring, and (ii) combining each series of springs by an equivalent elastic-plastic spring, which retains all the relevant characteristics, leading to a general non-linear equivalent elastic model for the analysis of minor axis beam-to-column joints.

The six-degree-of-freedom of the equivalent elastic model, Fig. 3, are:

- $q_{1} \rightarrow$ total rotation of the joint $\left(q_{1}=\phi\right)$;

- $q_{2} \rightarrow$ rotation of the rigid links (length $L_{c}$ ) in compression zone (index $c$ ); 

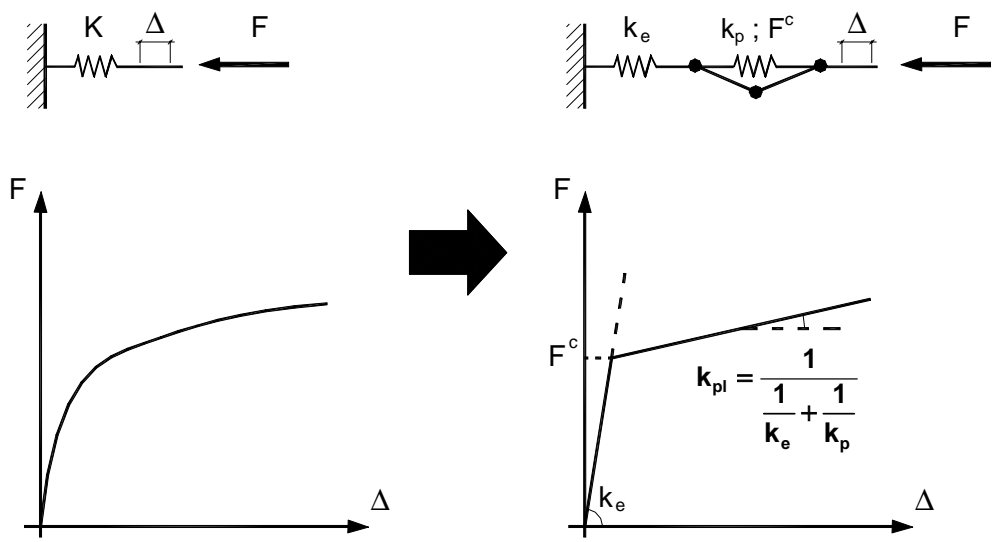

Fig. 2. Equivalent elastic model for a spring in compression.
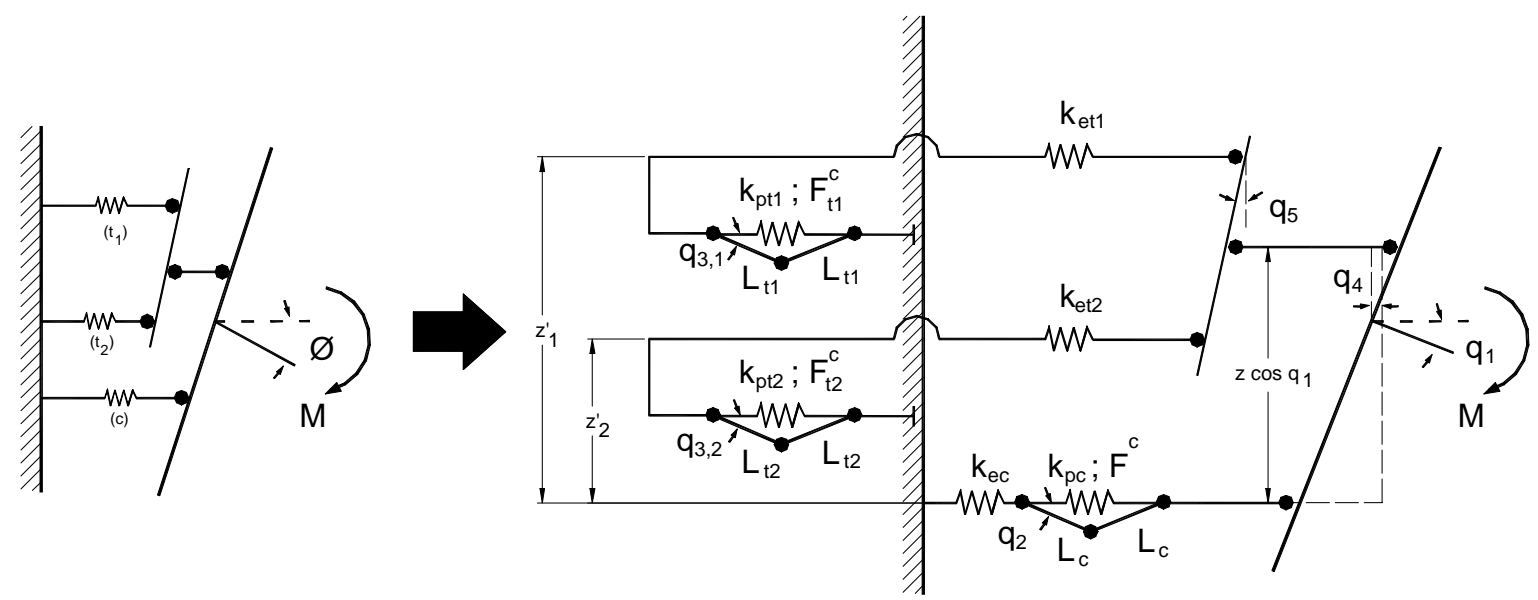

Fig. 3. Equivalent elastic model for the analysis of beam-to-column joints.

- $q_{3_{i}} \rightarrow$ rotation of the rigid links (length $L_{t_{i}}$ ) in tension zone (index $c$ ), $i=1,2$;

- $q_{4} \rightarrow$ joint axial displacement;

- $q_{5} \rightarrow$ tensile zone joint rotation;

Finally, the model is analysed with a post-buckling stability analysis using an energy-based formulation. Full details of the mathematical derivation can be found in Ref. [11]. Direct application of this model will be used throughout the paper in all analytical calculations for the moment-rotation response of the joints. 

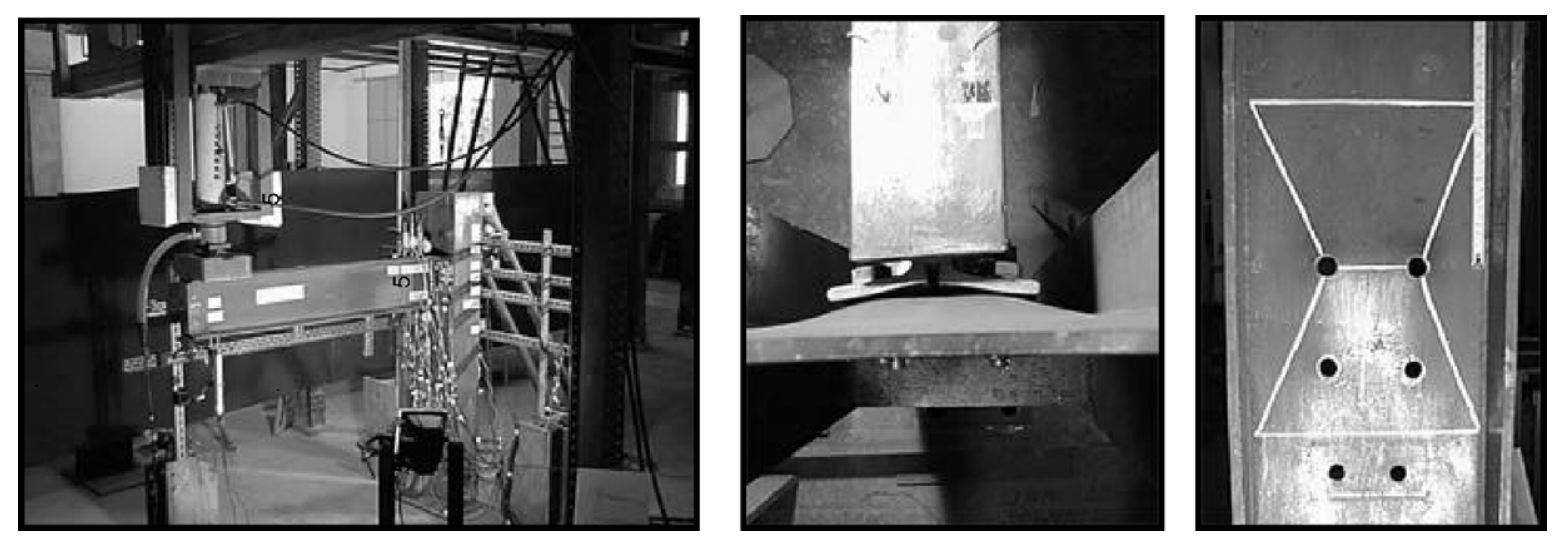

Fig. 4. Experimental test layout and connection's final configuration, first test.

Table 2

Experimental test geometric characteristics

\begin{tabular}{lllll}
\hline Test & Beam & Column (similar to) & Bottom support & Double web angle \\
\hline 1 & I $254 \times 37.7$ & HEA 300 & \rfloor $76 \times 76 \times 9.5$ & \rfloor$\lfloor 76 \times 76 \times 9.5$ \\
2 & I $254 \times 37.7$ & HEA 300 & Plate $270 \times 90 \times 9.5$ & \rfloor$\lfloor 127 \times 76 \times 9.5$ \\
3 & I $254 \times 37.7$ & HEA 300 & Plate $270 \times 90 \times 9.5$ & \rfloor$\lfloor 127 \times 76 \times 9.5$ \\
\hline
\end{tabular}

\section{Experimental programme}

The experimental investigation comprehended three experimental tests using a cantilever-loading beam, Fig. 4. This figure also presents a top view of the residual deformation shape in the column web of the first test together with the column web yield line pattern. The beams ( $\mathrm{S}$ shapes) and angles were composed of rolled steel sections and the column was a welded steel section (similar $\mathrm{W}$ shapes) due to economy reasons [12].

The steel profiles used in the three experimental tests are detailed in Table 2. The bolts used in the connection were of high strength type of ASTM A325 with a $19.05 \mathrm{~mm}$ diameter. The columns steel grade used $250 \mathrm{MPa}$ yield strength while for the beams and angles the ASTM A36 steel grade was adopted. The measured steel yield and ultimate stress measured in the beam, column, first test angles and other angles, obtained in accordance with ASTM E8-69, were: 364, 497, 309, 419, 325, 472, 417 , and $528 \mathrm{MPa}$, respectively. In the first test, due to the web plate flexibility, large deformations occurred. The maximum applied load reached $25.3 \mathrm{kN}$ (corresponding to a $38.0 \mathrm{kN} \mathrm{m}$ connection moment) when the load cell slipped out due to the large rotation present in the cantilever beam end.

The first connection detail of the executed test is illustrated in Fig. 5. In the second and third tests, a stiffener substituting the seat angle and the web angle was adopted with unequal legs $(127 \times$ $76 \times 9.5 \mathrm{~mm}$ ) to facilitate the assembly, Fig. 6 . In the third test, a stiffener was used in the column web close to the top flange of the beam.

In Fig. 7 the maximum web centreline displacements (in $\mathrm{mm}$ ) in the column web and the deformations presented in the web angle are depicted. The web angle reached the yield deformation 

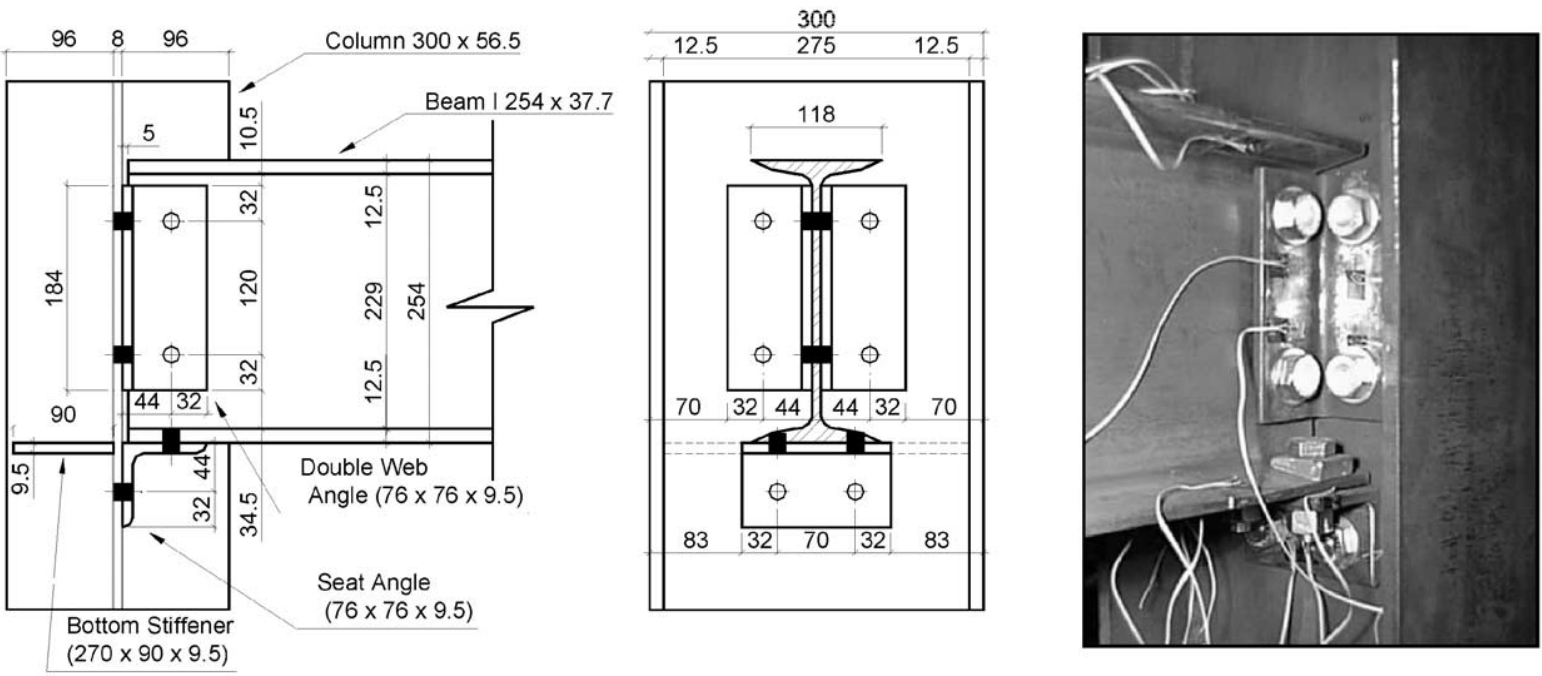

Fig. 5. Detail of the first connection tested (dimensions in $\mathrm{mm}$ ).
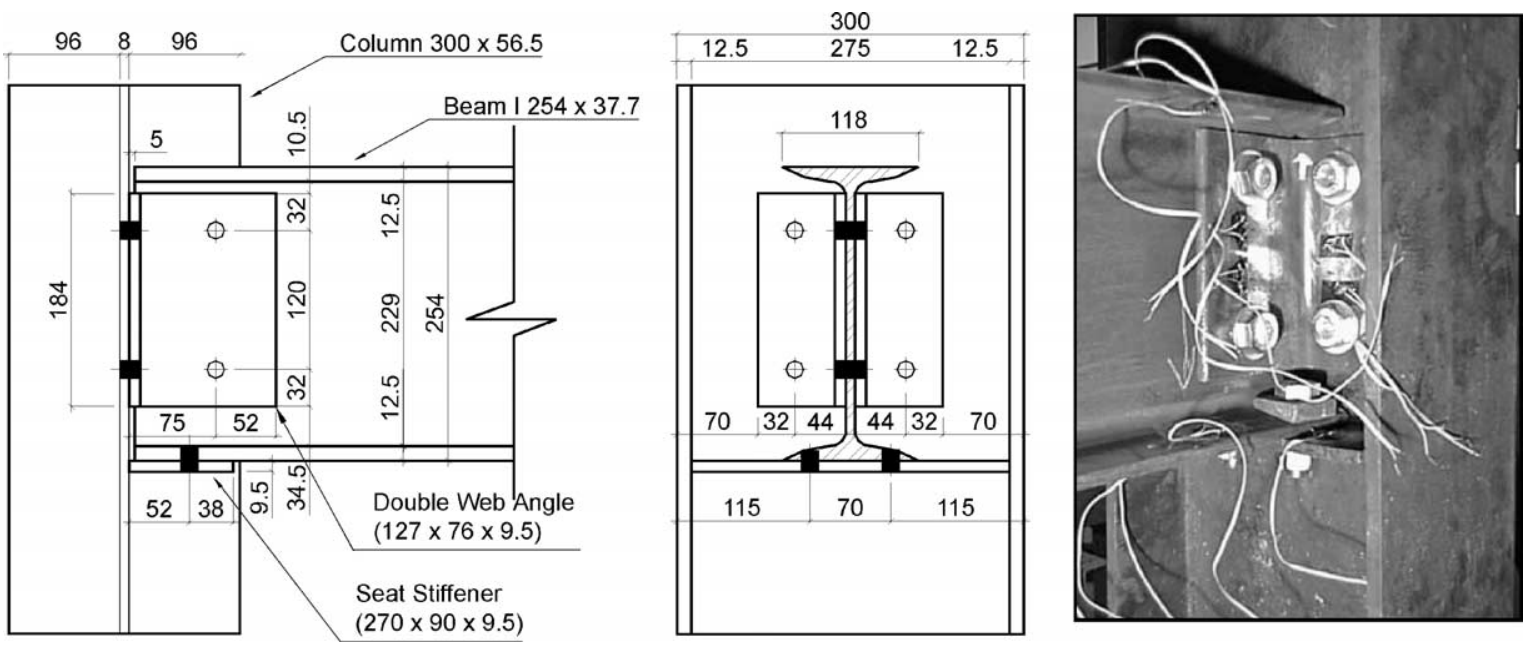

Fig. 6. Detail of the second connection tested (dimensions in $\mathrm{mm}$ ).

for a load of approximately $15.0 \mathrm{kN}$ indicating the beginning of a yield line formation. The column web displacement (in $\mathrm{mm}$ ) and the web angle deformation for the second test are shown in Fig. 8. In this test, unlike the first test, the yield deformation was not reached. Fig. 9 presents web angle deformation and column web displacements for the third test. It can be observed that the web angle reached the yield deformation for a load of $25.0 \mathrm{kN}$, higher than the value reached in the first test.

The column web normalised vertical stresses (all stresses were divided by the web yield stress) are presented in Figs. 10-12. It is noticed from these deformations that the second test presented a smoother stress variation when compared to the first test. Same deformation levels were reached for the first and second tests with a loads of: 14.1 and $20.0 \mathrm{kN}$, respectively. The top stiffener used 

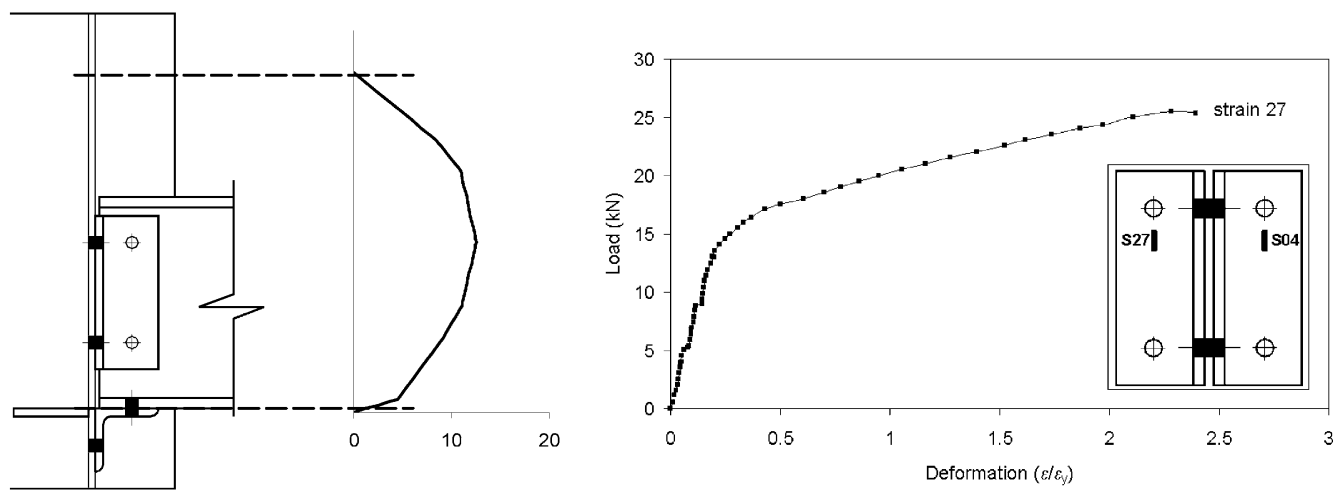

Fig. 7. Column web displacements and web angle deformations, first test.
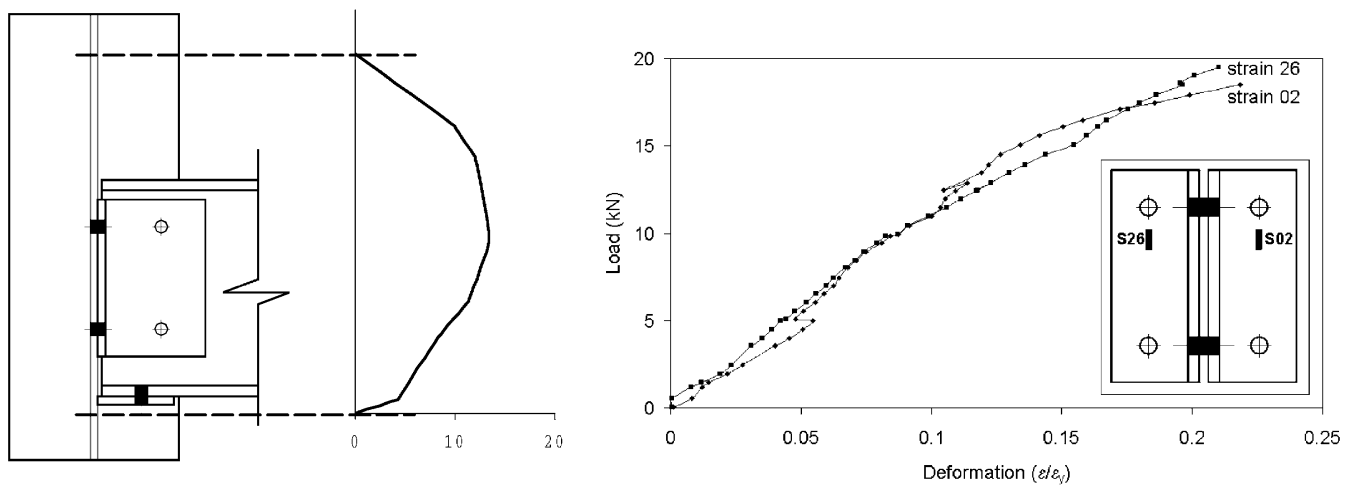

Fig. 8. Column web displacements and web angle deformation, second test.
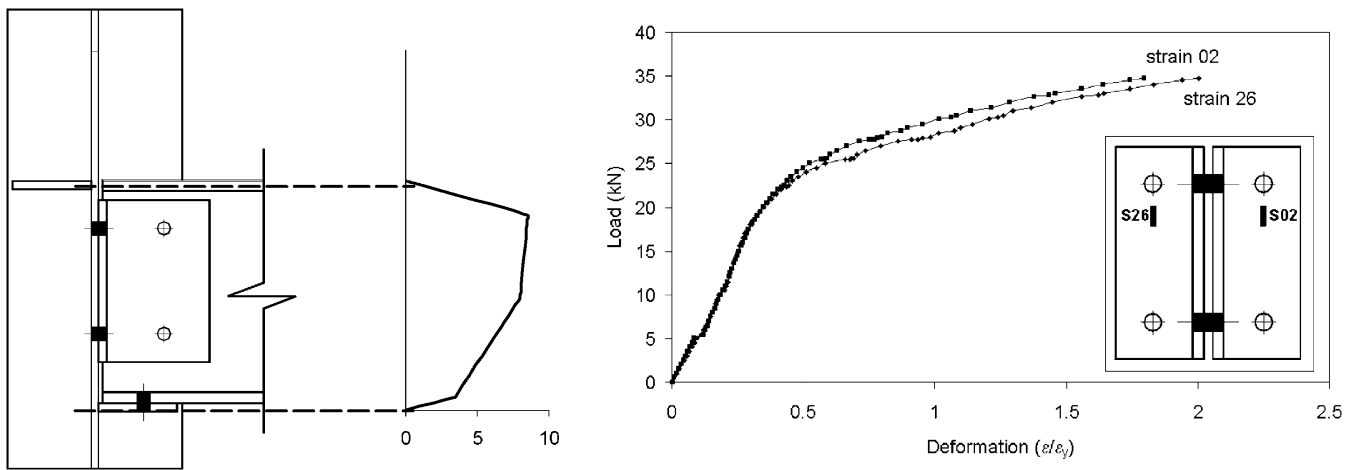

Fig. 9. Column web displacement and web angle deformations, third test. 
Load: $5.0 \mathrm{kN}$

Moment: 7.1 kN.m

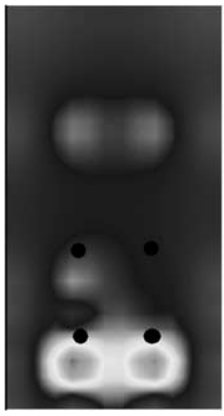

Load: $9.4 \mathrm{kN}$

Moment: 13.4 kN.m

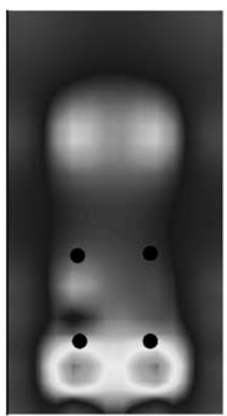

Load: $11.9 \mathrm{kN}$

Moment: $16.9 \mathrm{kN} . \mathrm{m}$

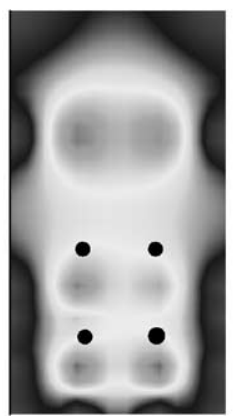

Load: $14.1 \mathrm{kN}$ Moment: $20.0 \mathrm{kN} . \mathrm{m}$

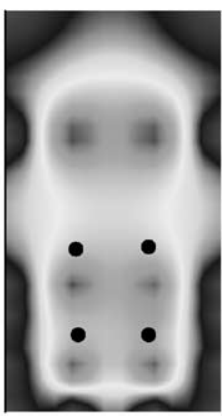

Fig. 10. Column web normalised vertical stress evolution, first test.

Load: $9.5 \mathrm{kN}$ Moment: $13.5 \mathrm{kN} . \mathrm{m}$

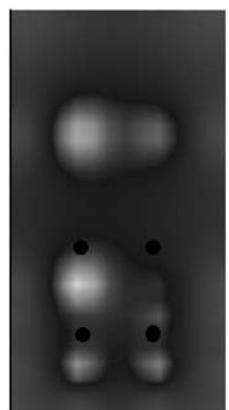

Load: $12.4 \mathrm{kN}$ Moment: $17.7 \mathrm{kN} . \mathrm{m}$

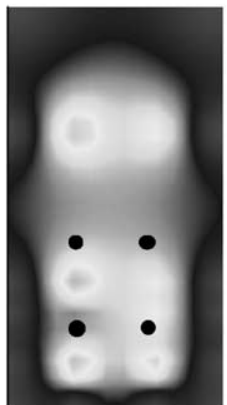

Load: $16.0 \mathrm{kN}$ Moment: $22.8 \mathrm{kN} . \mathrm{m}$

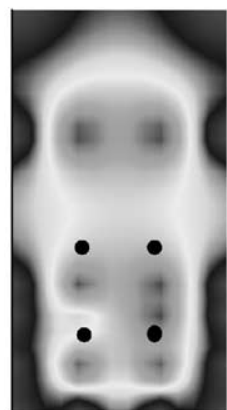

Load: $20.0 \mathrm{kN}$ Moment: $28.5 \mathrm{kN} . \mathrm{m}$

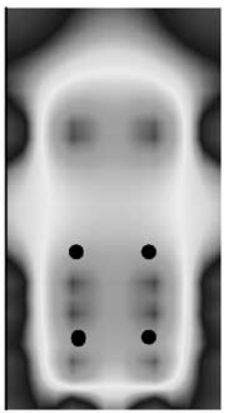

Fig. 11. Column web normalised vertical stress evolution, second test.

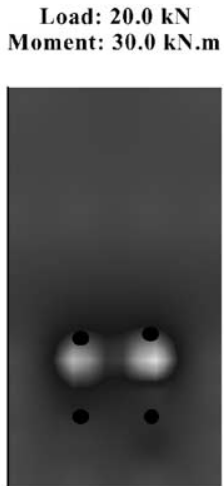

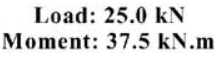

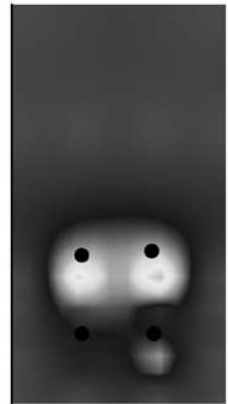

Load: $30.0 \mathrm{kN}$ Moment: $45.0 \mathrm{kN} . \mathrm{m}$

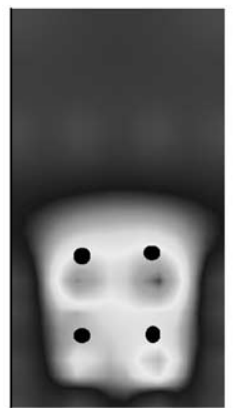
Moment: $52.0 \mathrm{kN} . \mathrm{m}$

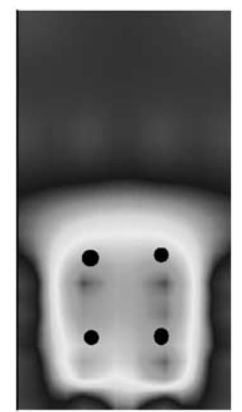

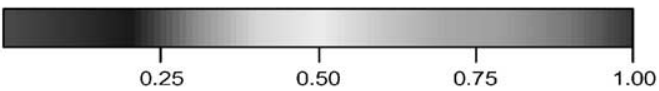

Fig. 12. Column web normalised vertical stress evolution, third test. 


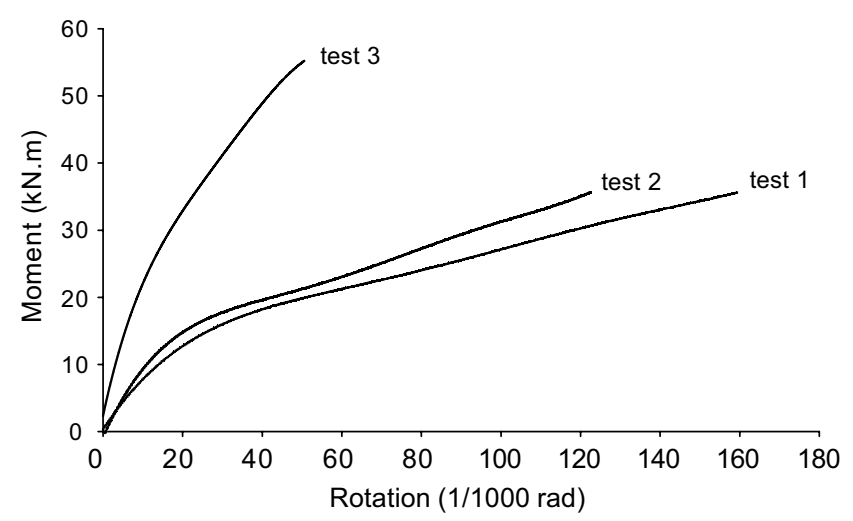

Fig. 13. Moment versus rotation curves of the experimental tests.

in the third test reduced the column web deformations substantially. Moment versus rotation curves for all the experiments are presented in Fig. 13.

\section{The finite element simulations}

The finite element type used to model only the column web and flanges was the eight-noded shell element. This strategy leads to much lighter models than solid elements (that need much more computational effort) and may cope with the relevant deformations: bending, and membrane as stated by Neves and Gomes [13]. The column flanges were considered coupled with the common nodes of the column web. The adopted finite element program, ANSYS, enables the material and geometric non-linearity to be taken into account. The finite element mesh used to model the first test column is represented in Fig. 14. The boundary conditions were: all base nodes fixed in $z$ direction, one base node full fixed and another, in opposite side, fixed in $y$ and $z$ directions. The load was applied through prescribed displacements in the position of the four bolts in the column web. The material non-linearity was considered by using a Von Mises yield criterion associated with a three-linear stress-strain relationship to incorporate strain hardening. The geometrical non-linearity was introduced in the model by using a updated Lagrangean formulation. A validation of the finite element model simulation was performed through a comparison with the experimental results, Fig. 15. In this graph, load versus displacement curves for three points (A, B and C) located in the column web, Fig. 14, depicted a good agreement between experimental and finite element simulations. The experimental curve was obtained with the aid of displacement transducers as it can be observed in Fig. 16.

The principal stresses at the last load step, calculated through a Von Mises yield criteria, is depicted in Fig. 17 where it is possible to observe that a large part of the web panel has yielded.

To investigate the influence of the column web thickness, the experimental column web thickness, $8 \mathrm{~mm}$, was changed to 6.3 and $10 \mathrm{~mm}$ keeping all the other profile test dimensions (corresponding to $43.65,37.37$ and 27.5 , column web slenderness). The bilinear model was applied to the finite element results generating $k_{e}$ and $k_{p l}$ stiffness values for the three investigated column web thickness, 


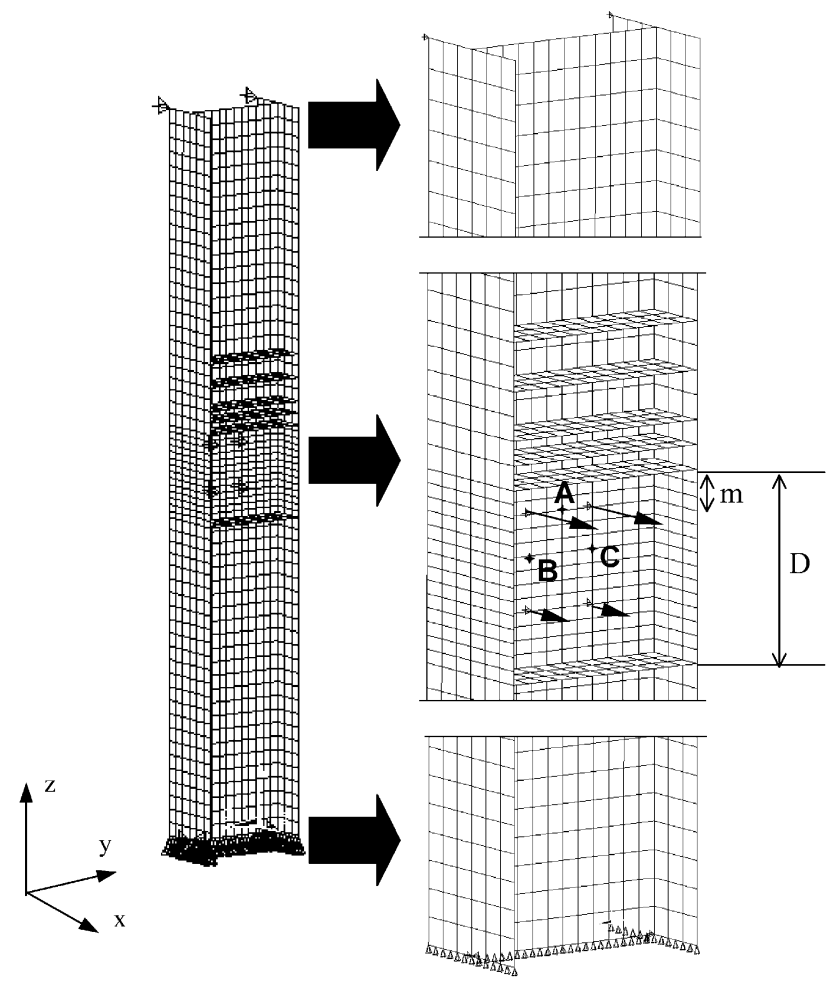

Fig. 14. Finite element mesh, load application points and boundary conditions of the finite element model.

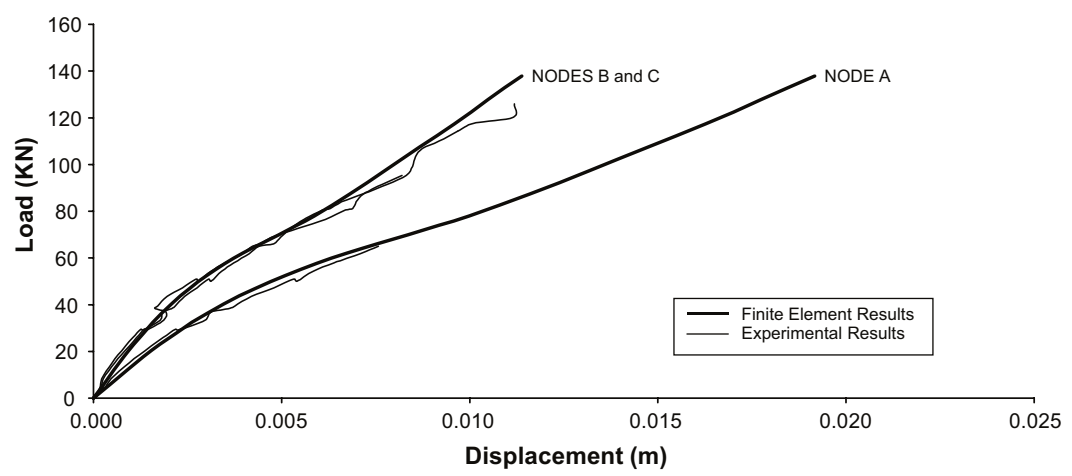

Fig. 15. Experimental results calibration.

Table 3. The values of $k_{e}$ and $k_{p l}$ were obtained as the slope of the straight lines that best fit the curve points, for the elastic and plastic parts, respectively. The column web in bending component stiffness, $k_{21}$, was determined dividing the $k_{e}$ stiffness, determined in Fig. 18 curves, by Young's modulus.

The finite element simulations proceeded focusing on the distance between the stiffeners. Six combinations were simulated with the ANSYS program keeping all the other dimensions, Fig. 19. 

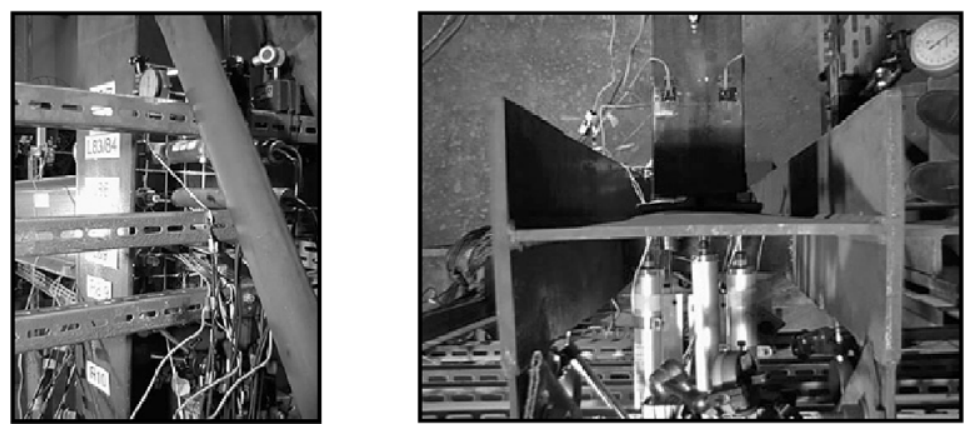

Fig. 16. Displacements transducers for the first test (general layout and top view).
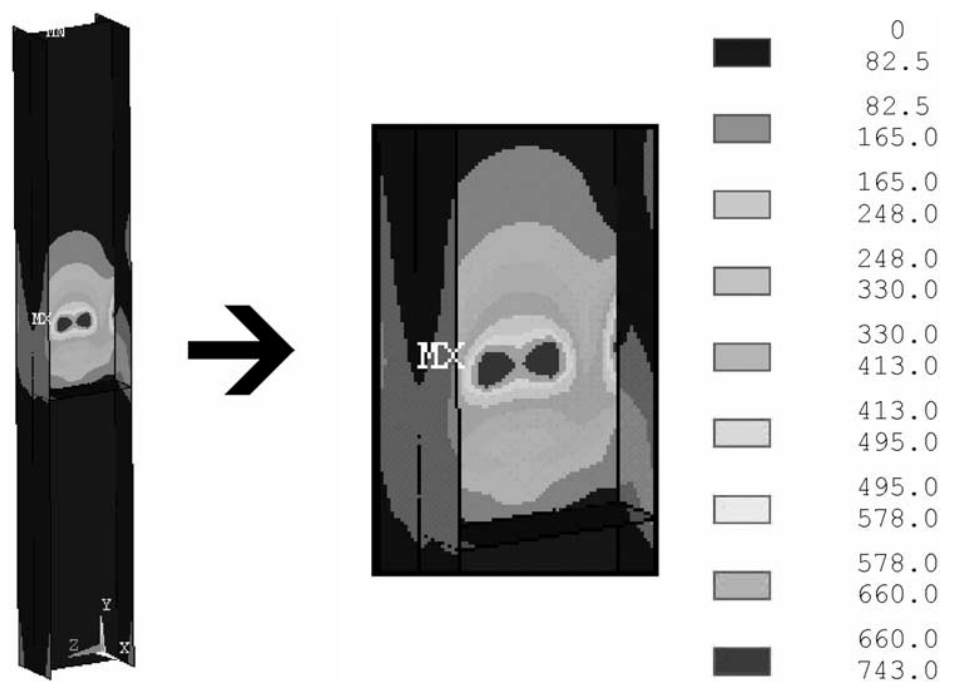

Fig. 17. Principal stresses (MPa) calculated through Von Mises yield criteria.

Table 3

Influence of the column web thickness over the connection stiffness

\begin{tabular}{ccclc}
\hline$t_{w}(\mathrm{~mm})$ & $h / t_{w}$ & $k^{e}(\mathrm{kN} / \mathrm{m})$ & $k^{p}(\mathrm{kN} / \mathrm{m})$ & $k_{21}(\mathrm{~m})$ \\
\hline 6.3 & 43.7 & 3715.0 & 2312.1 & 0.018 \\
8.0 & 34.4 & 6529.4 & 2087.5 & 0.032 \\
10.0 & 27.5 & 11933.3 & 1786.4 & 0.058 \\
\hline
\end{tabular}

The load versus displacement curves obtained are presented in Fig. 20. With the aid of these curves can be obtained the value of $k_{21}$, i.e., the elastic stiffness of the column web loaded chord in bending, Table 4. 


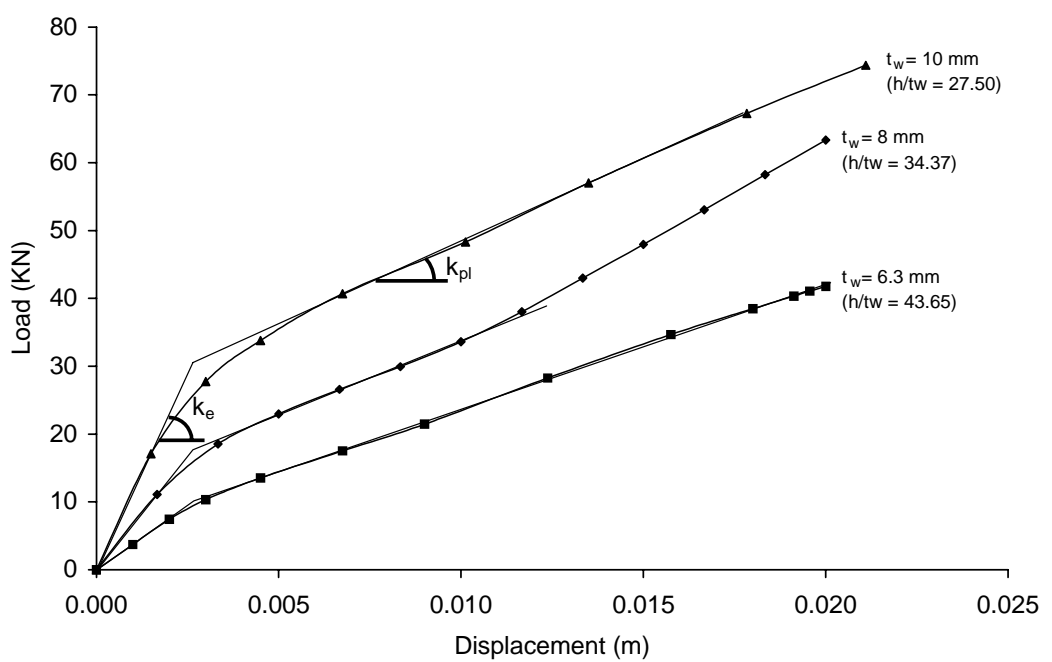

Fig. 18. Influence of the column web thickness over the connection structural response.

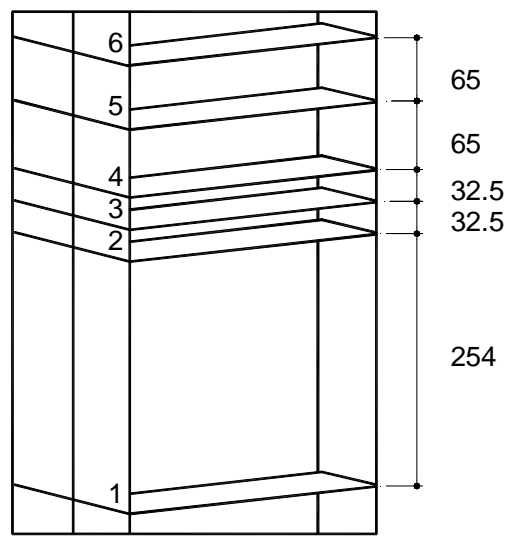

Fig. 19. Column web stiffeners location layout (distance in $\mathrm{mm}$ ).

\section{Evaluation of the new component, $k_{21}$}

Neves and Gomes [14] concluded that the column web of minor axis joints could be modelled as a plate supported at the junction with the flanges and free in the other borders. This model, represented in Fig. 21, has a length equal to $L$ and a width $l_{e f f}$ that depends on the dimensions of the loaded area:

$$
\begin{aligned}
& l_{e f f}=c+(L-b) \operatorname{tg} \theta, \\
& \frac{l_{e f f}}{L}=\alpha+(1-\beta) \operatorname{tg} \theta,
\end{aligned}
$$

where $\alpha=c / L$ for $0.05 \leqslant \alpha \leqslant 0.20$ and $\beta=b / L$ for $0.08 \leqslant \beta \leqslant 0.75$. 


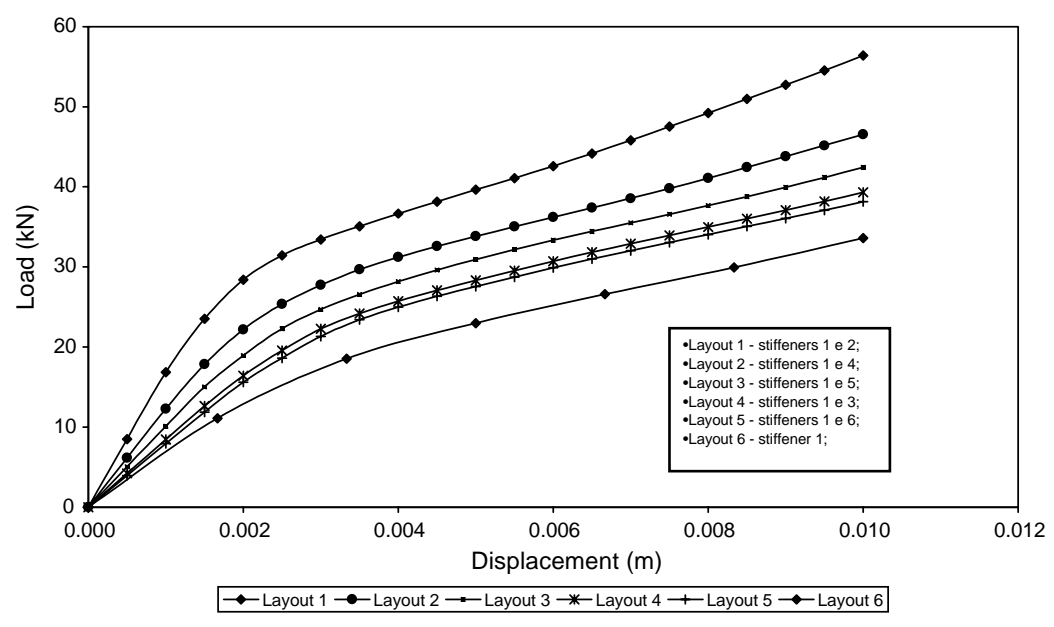

Fig. 20. Influence of the column web stiffeners over the connection structural response.

Table 4

Comparison of the values of $k_{21}$ obtained by FEM and by Eq. (9)

\begin{tabular}{lll}
\hline Layout & $k_{21 \text { FEM }}(\mathrm{mm})$ & $k_{21 \text { equation }}(\mathrm{mm})$ \\
\hline 1 & 82.1 & 79.4 \\
2 & 59.9 & 63.9 \\
3 & 49.3 & 53.7 \\
4 & 41.3 & 41.7 \\
5 & 38.7 & 35.6 \\
6 & 32.0 & 33.4 \\
\hline
\end{tabular}

In Fig. 22, some dimensions, that are necessary to evaluate the model, are presented:

$$
\begin{aligned}
& L=d-1.5 r, \\
& b=b_{0}+0.9 d_{m}, \\
& c=c_{0}+0.9 d_{m}, \\
& d_{m}=\frac{d_{1}+d_{2}}{2},
\end{aligned}
$$

where $d$ is the column height, $r$ is the root radius for rolled sections or throat thickness for welded sections.

The initial stiffness of this strip, computing flexural and shear deformations, may be easily expressed by Eq. (7).

$$
k_{21}=\frac{2 l_{e f} t_{w c}^{3}}{a^{3}+2(1+v) a t_{w c}^{2}},
$$

where $a=0.5(L-b), t_{w c}$ is the column web thickness and $v$ the Poisson's coefficient. 


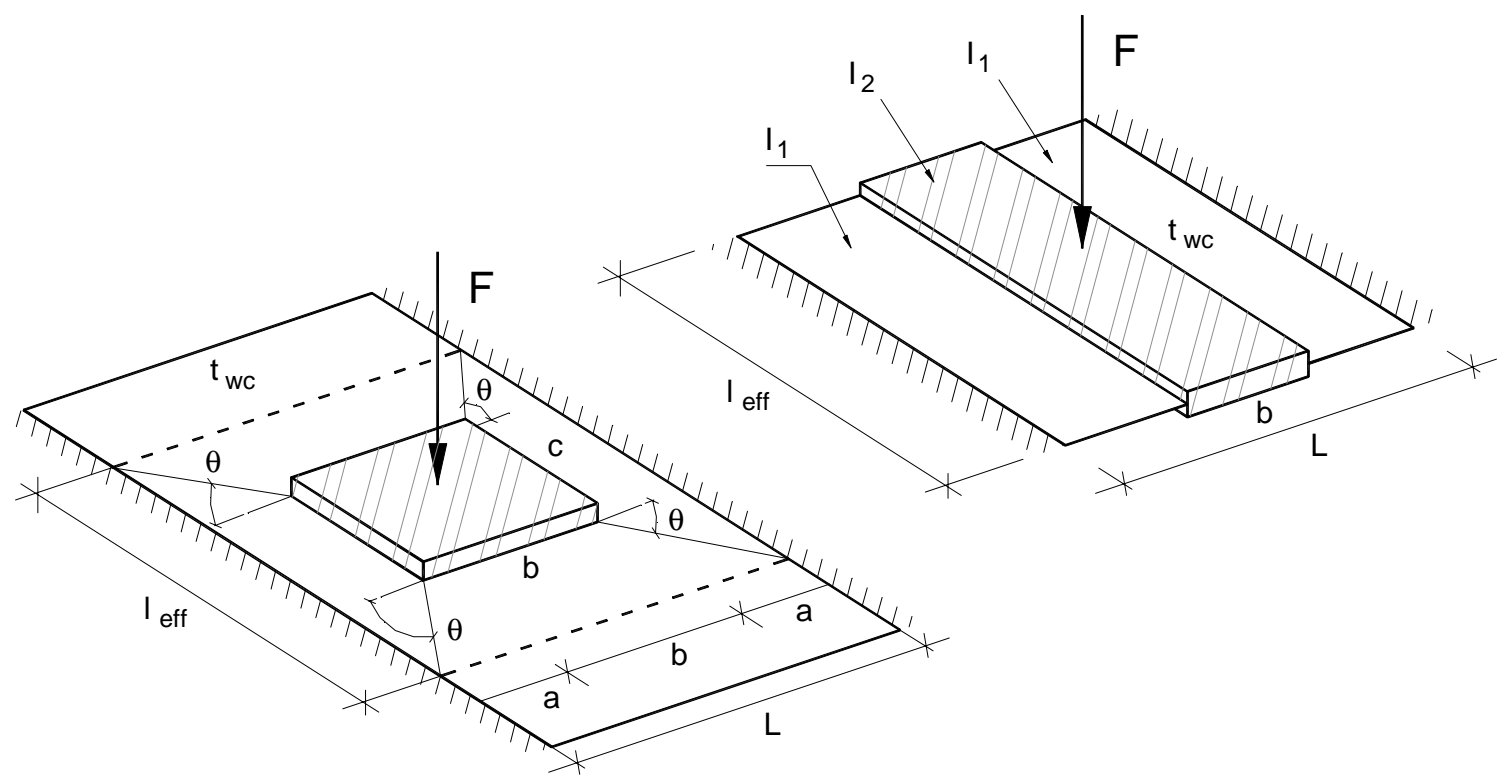

Fig. 21. Column web loaded by a rigid area $b \times c$ and equivalent strip of width $l_{\text {eff }}$.
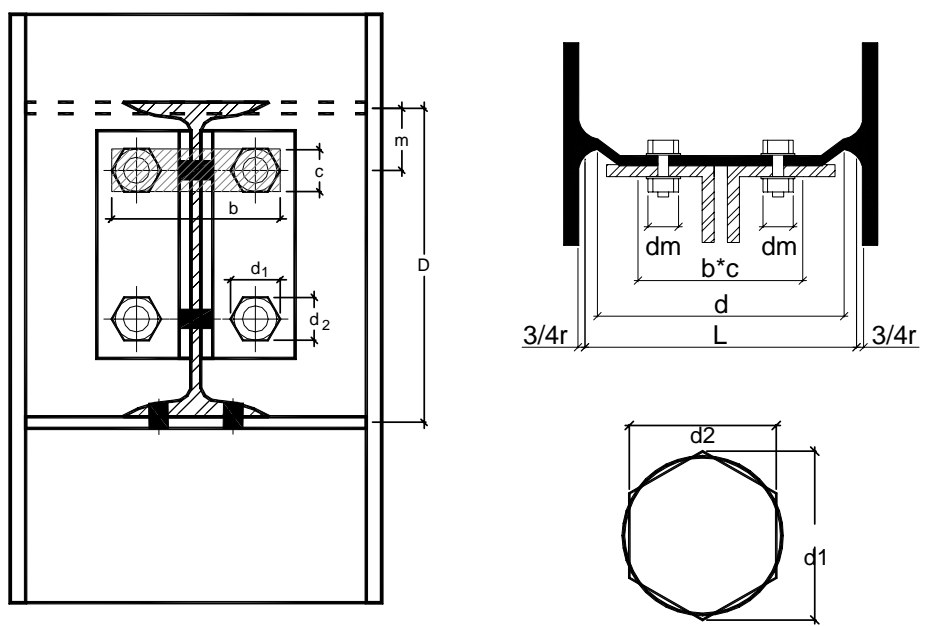

Fig. 22. Geometric characteristics of the minor axis-joint.

Substituting the value of $a$ and $l_{e f f}$, taking Poisson's coefficient equal to 0.3 , introducing two new coefficients $k_{1}$ and $k_{2}$, Eq. (8) is obtained.

$$
k_{21}=16 \frac{t_{w c}^{3}}{L^{2}} \frac{\alpha+(1-\beta) \tan \theta}{(1-\beta)^{3}+\left(10.4\left(k_{1}-k_{2} \beta\right)\right) / \mu^{2}},
$$

where $\mu=L / t_{w c}, k_{1}=1.5, k_{2}=1.63$ and $\theta=35-10 \beta$. 
Eq. (8) does not consider the influence of column web stiffeners. A polynomial approximation was introduced to tackle this effect leading to Eq. (9). In this equation, $m$ represents the distance between the top stiffener and the load application point; and $D$, the distance between the stiffeners, Fig. 22.

$$
k_{21}=16 \frac{t_{w c}^{3}}{L^{2}} \frac{\alpha+(1-\beta) \tan \theta}{(1-\beta)^{3}+\left(10.4\left(k_{1}-k_{2} \beta\right)\right) / \mu^{2}}\left[0.57\left(\frac{m}{D}\right)^{2}-0.85\left(\frac{m}{D}\right)+0.41\right] .
$$

The comparison between the values obtained by the finite element simulations and by Eq. (9) can be observed in Table 4.

\section{Application of the model to beam-to-column joints}

In order to illustrate the application of the proposed model, an evaluation of the stiffness for the first test will be presented. Assuming a bi-linear approximation to the $F-\Delta$ response of each component, three properties must be characterised: $k_{e}, k_{p l}$ and $F_{c}$. Both resistance and initial stiffness for the joint components were determined according to Eurocode 3 and Faella et al. [15], using 1.0 for all the partial safety factors. The post-limit stiffness was numerically adjusted from the test results and combined to yield an equivalent stiffness $k_{p l}$ for each bolt row, Table 5. Experimental values were used to evaluate the component 21 .

After the assessment of all the elastic stiffness components, it was possible to obtain the model's moment versus rotation curve and the initial stiffness. The initial stiffness evaluation according to the Eurocode 3, requires a previous knowledge of the first tension bolt row effective stiffness coefficient, that is obtained coupling by a set of springs in series, Eq. (10).

$$
k_{e f, r}=\frac{1}{\sum_{i} 1 / k_{i, r}}
$$

where $k_{i, r}$ is the stiffness coefficient representing $i$ component relative to the $r$ bolt row.

This strategy led to $k_{e f, t 1}=45703.8 \mathrm{kN} / \mathrm{m},(11)$. The same process was executed for the second tension bolt row and the compression bolt row leading to values of: $k_{e f, t 2}=45767.6 \mathrm{kN} / \mathrm{m}(12)$, and $k_{e f, c}=104263.59 \mathrm{kN} / \mathrm{m},(13)$, respectively.

$$
\begin{aligned}
& k_{e f, t 1}=\frac{1}{1 / k_{6,1}+1 / k_{8,1}+1 / k_{10,1}+1 / k_{11,1}+1 / k_{12 b w, 1}+1 / k_{12 w a, 1}+1 / k_{21,1}}, \\
& k_{e f, t 2}=\frac{1}{1 / k_{6,2}+1 / k_{8,2}+1 / k_{10,2}+1 / k_{11,2}+1 / k_{12 b w, 2}+1 / k_{12 w a, 2}+1 / k_{21,2}}, \\
& k_{e f, c}=\frac{1}{1 / k_{7}+1 / k_{11}+1 / k_{12 b f}+1 / k_{12 s a}} .
\end{aligned}
$$

Using Eq. (14), the equivalent stiffness of the tensile zone can be obtained, $k_{e q}=75946.9 \mathrm{kN} / \mathrm{m}$, with $z_{e q}=0.16 \mathrm{~m}$, Eq. (15).

$$
k_{e q, t}=\frac{\sum_{r} k_{e f, r} h_{r}}{z_{e q}}=\frac{k_{e f, t 1} z_{1}+k_{e f, t 2} z_{2}}{z_{e q}}
$$


Table 5

Component method evaluation, first test

\begin{tabular}{|c|c|c|c|c|}
\hline Component & $\begin{array}{l}F^{c} \\
(\mathrm{kN})\end{array}$ & $\begin{array}{l}k_{e}^{\prime} \\
(\mathrm{mm})\end{array}$ & $\begin{array}{l}k_{e} \\
(\mathrm{kN} / \mathrm{m})\end{array}$ & $\begin{array}{l}k_{p l}{ }^{\mathrm{a}} \\
(\mathrm{kN} / \mathrm{m})\end{array}$ \\
\hline \multicolumn{5}{|l|}{ First tension bolt row } \\
\hline 6 web angle in bending & 106.49 & 1.03 & 211150 & \multirow{7}{*}{21648000} \\
\hline 8 beam web in tension & 207.36 & $\infty$ & $\infty$ & \\
\hline 10bolts in tension & 186.61 & 12.57 & 2576850 & \\
\hline 11 bolts in shear & 155.51 & 1.61 & 330050 & \\
\hline $12^{b w}$ beam web in bearing & 85.33 & 0.69 & 141450 & \\
\hline $12^{w a}$ web angle in bearing & 101.33 & 0.75 & 153750 & \\
\hline 21 column web in bending & 18.50 & 32.00 & 6560000 & \\
\hline \multicolumn{5}{|l|}{ Second tension bolt row } \\
\hline 6 web angle in bending & 106.49 & 1.03 & 211150 & \multirow{7}{*}{12772500} \\
\hline 8 beam web in tension & 207.36 & $\infty$ & $\infty$ & \\
\hline 10bolts in tension & 186.61 & 12.57 & 2576850 & \\
\hline 11 bolts in shear & 155.51 & 1.61 & 330050 & \\
\hline $12^{b w}$ beam web in bearing & 85.33 & 0.69 & 141450 & \\
\hline $12^{w a}$ web angle in bearing & 101.33 & 0.75 & 153750 & \\
\hline 21 column web in bending & 50.00 & 40.00 & 8200000 & \\
\hline \multicolumn{5}{|l|}{ Compression bolt row } \\
\hline 7beam flange in compression & 503.11 & $\infty$ & $\infty$ & \multirow{4}{*}{8028} \\
\hline 11 bolts in shear & 155.51 & 1.61 & 330050 & \\
\hline $12^{b f}$ beam flange in bearing & 85.33 & 0.69 & 141450 & \\
\hline $12^{s a}$ seat angle in bearing & 101.33 & 0.75 & 153750 & \\
\hline
\end{tabular}

${ }^{\mathrm{a} E v a l u a t e d ~ f o r ~ e a c h ~ b o l t ~ r o w ~ o n l y . ~}$

where $h_{r}$ is the distance between the $r$ bolt row and the compression centre, $k_{e f, r}$ is the effective stiffness coefficient for the $r$ bolt row taking into account the $k_{i}$ stiffness coefficient and $z_{e q}$ is the equivalent lever arm calculated by Eq. (15).

$$
z_{e q}=\frac{\sum_{r} k_{e f, r} h_{r}^{2}}{\sum_{r} k_{e f, r} h_{r}}=\frac{k_{e f, t 1} z_{1}^{2}+k_{e f, t 2} z_{2}^{2}}{k_{e f, t 1} z_{1}+k_{e f, t 2} z_{2}} .
$$

When all these steps are performed, the initial stiffness can be determined through Eq. (16), yielding $S_{j, \text { ini }}=1122.6 \mathrm{kN} \mathrm{m} / \mathrm{rad}$. This value proved to be a very accurate approximation of the experimental value, $S_{j, \exp }=1228.1 \mathrm{kN} \mathrm{m} / \mathrm{rad}$.

$$
S_{j, i n i}=\frac{z_{e q}^{2}}{1 / k_{e q, t}+1 / k_{e f, c}} .
$$

\section{Conclusions}

The use of semi-rigid connections has been significantly increased over the last few years. In one attempt of representing the connections true behaviour, many models were proposed, mainly for the major axis. When the minor axis is considered, the knowledge is still very limited. A non-linear 


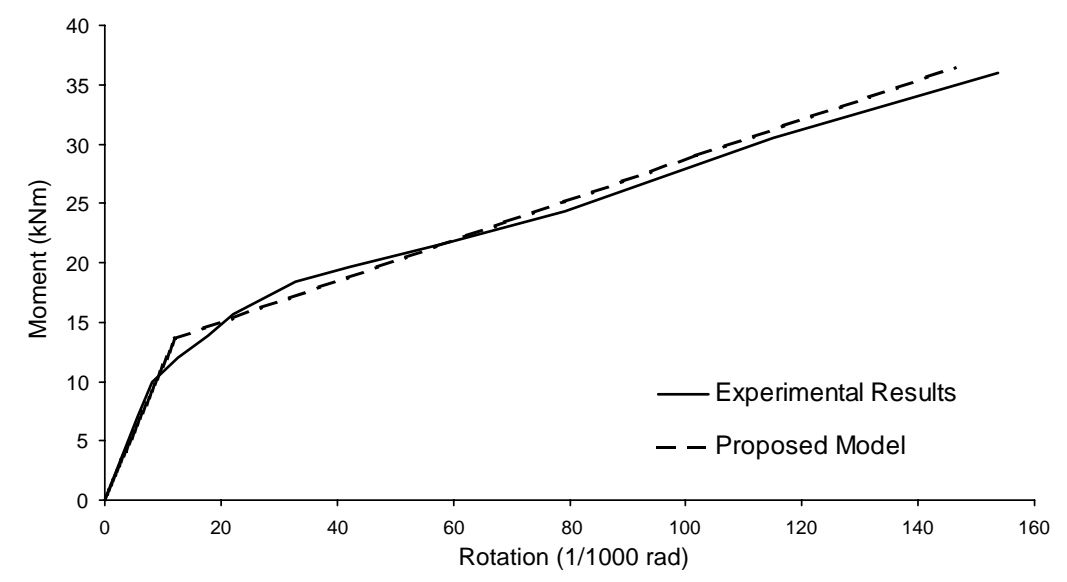

Fig. 23. Moment versus rotation curve, test 1: comparison between experimental results and proposed model.

finite element analysis of minor axis connections was also performed using the ANSYS program. The finite element simulations focused on the column web thickness and the influence of column web stiffeners.

It can be concluded that the column web thickness is one of the most important factors affecting the joint strength and stiffness. On the other hand, the contribution of the column web stiffeners was found to be equally important. Therefore designers should position the top stiffeners as close as possible to the bolt's top row.

A semi-rigid design model, based on the spring model concept adopted in the Eurocode 3, for minor axis frame connections, was conceived. The model can be applied to any kind of joint (major or minor axis) as a set of components (springs) assembled in series or/and in parallel.

The comparison between curves obtained from the proposed model and the experimental results can be observed in Fig. 23. Clearly, a good agreement was reached in terms of initial stiffness and moment resistance. Although this paper only presented an approximation of the post-limit stiffness the full explanation of this topic can be found in by Silva et al. [11].

The main contribution of this paper is to present a simple method of assessment for minor axis semi-rigid beam to column joints.

\section{Acknowledgements}

Financial support from “CAPES — Coordenação de Aperfeiçoamento de Pessoal de Nível SuperiorBrazil" is gratefully acknowledged.

\section{References}

[1] Jaspart J-P. General report: session on connections Journal of Constructional Steel Research 2000;55:69-89.

[2] Zoetemeijer P. A design method for the tension side of statically-loaded, bolted beam-to-column joints. Heron $1974 ; 20(1): 1-59$. 
[3] Yee YL, Melchers RE. Moment-rotation curves for bolted connections. Journal of Structural Engineering, ASCE 1986;112(3):615-35.

[4] Jaspart J-P. Etude de la semi-rigidité des noeuds poutre-colonne et son influence sur la resistance des ossatures en acier. Ph.D. thesis, Department MSM, University of Liége, Belgium, 1991 (in French).

[5] Silva LS, Coelho AG. A ductility model for steel connections. Journal of Constructional Steel Research 2001;57: 45-70.

[6] Eurocode 3. prEN-1993-1-8: 20xx, Part 1.8: Design of joints, Eurocode 3: design of steel structures, Draft 2 Revisions. CEN, European Committee for Standardisation, Brussels, 6 December 2000.

[7] Lima LRO. Evaluation of minor-axis beam-to-column steel joints subjected to bending. M.Sc. thesis, Civil Engineering Department, PUC-RIO, Brazil, 1999 (in Portuguese).

[8] ANSYS-Basic Analysis Procedures Guide, 3rd ed. Release 5.5, September 1998.

[9] Weynand K, Jaspart J-P, Steenhuis M. The stiffness model of Revised Annex J of Eurocode 3. In: Bjorhovde R, Colson A, Zandonini R, editors. Connections in steel structures III. Proceedings of the Third International Workshop on Connections, Trento, Italy, 1995. p. 441-52.

[10] Neves LFC. Semi-rigid connections in steel structures. Assessment of stiffness for minor-axis geometries. M.Sc. thesis, University of Coimbra, Coimbra, Portugal, 1996 (in Portuguese).

[11] Silva LS, Coelho AG, Simões R. Analytical evaluation of the moment-rotation response of beam-to-column composite joints under static loading. International Journal of Steel and Composite Structures 2001;1(2):245-68.

[12] Lima LRO, Vellasco PCGS, Andrade SAL. Bolted semi-rigid connections to the column minor axis. In: Studnicka J, Wald F, Machacek J, editors. Proceedings of the second European Conference on Steel Structures, Eurosteel '99, Czech Technical University in Prague, Prague, 1999. p. 473-6.

[13] Neves LC, Gomes F. In: Virdi KS, editor. Guidelines for a numerical modelling of beam-to-column minor-axis joints, COST C1 Report of W.G. 6-Numerical Simulation, European Commission, Brussels, 1999. p. 48-60.

[14] Neves LC, Gomes F. Semi-Rigid behaviour of beam-to-column minor-axis joints. In: Eth-Honggerberg, Zurich, Switzerland, Proceedings of the IABSE International Colloquium on Semi-Rigid Structural Connections, Istanbul, Turkey, 1996. p. 207-16.

[15] Faella C, Piluso V, Rizzano G. Structural steel semi-rigid connections: theory, design and software. Boca Raton FL: CRC Press LLC, 2000. 